\title{
Letter
}

\section{Is eosinopenia a reliable marker of sepsis?}

\author{
Alex Smithson ${ }^{1}$, Rafael Perelló ${ }^{2}$ and Josep-Maria Nicolas ${ }^{3}$
}

\begin{abstract}
${ }^{1}$ Infectious Diseases Unit, Hospital Clinic, IDIBAPS, University of Barcelona, 08036 Barcelona, Spain
${ }^{2}$ Emergency Department, Hospital Clínic, IDIBAPS, University of Barcelona, 08036 Barcelona, Spain

${ }^{3}$ Medical Intensive Care Unit, Hospital Clínic, IDIBAPS, University of Barcelona, 08036 Barcelona, Spain
\end{abstract}

Corresponding author: Alex Smithson, asa30412@hotmail.com

Published: 1 June 2009

This article is online at http://ccforum.com/content/13/3/409

(c) 2009 BioMed Central Ltd

See related research by Abidi et al., http://ccforum.com/content/12/2/R59

We have read with interest the article by Abidi and colleagues [1] in which the authors point out that eosinopenia could be useful to differentiate between noninfection and infection in patients recently admitted to an intensive care unit (ICU). The association of eosinopenia with infections is not new and has been described previously [2].

To test this hypothesis, we reviewed 191 patients (age $>18$ years, with a minimum ICU stay of 24 hours) admitted to
Critical Care 2009, 13:409 (doi:10.1186/cc7877)

the medical ICU of our hospital. We exuded HIV-infected patients and those with hematological malignancies. Total leukocyte and eosinophil count (EC) were measured at ICU admission. The results are shown in Table 1. Although the EC was lower and the proportion of patients with eosinopenia $(<40 \mathrm{cells} / \mathrm{ml})$ was higher in the noninfectious systemic inflammatory response syndrome (SIRS) group compared with the infectious SIRS group, these differences were not statistically significant. Therefore, the EC was not useful to

Table 1

\section{Baseline characteristics of the ICU patients included in the study}

\begin{tabular}{|c|c|c|c|}
\hline & Infectious SIRS ( $n=142)$ & Noninfectious SIRS $(n=49)$ & $P$-value* \\
\hline Age (years) & $62.7 \pm 15.3$ & $66.8 \pm 14.3$ & 0.1 \\
\hline APACHE II score & $16.6 \pm 6.5$ & $17.8 \pm 6$ & 0.27 \\
\hline SAPS II score & $36.6 \pm 12.1$ & $36.4 \pm 11.4$ & 0.95 \\
\hline SOFA score & $8.8 \pm 3.2$ & $7.7 \pm 2.7$ & 0.034 \\
\hline Length of ICU stay (days) & $11.4 \pm 11.3$ & $7.5 \pm 7.8$ & 0.03 \\
\hline \multicolumn{4}{|l|}{ Sites of infection } \\
\hline Community-acquired pneumonia & $57(40.1 \%)$ & NA & \\
\hline Hospital-acquired pneumonia & $9(6.3 \%)$ & NA & \\
\hline Urinary tract infection & $11(7.7 \%)$ & NA & \\
\hline Bacterial meningitis & $4(2.8 \%)$ & NA & \\
\hline Peritonitis & $23(16.2 \%)$ & NA & \\
\hline Other infections & $38(26.7 \%)$ & NA & \\
\hline ICU mortality & $39(27.4 \%)$ & $13(26.5 \%)$ & 0.89 \\
\hline Total leukocyte count (cells/ml) & $13,497 \pm 7,254$ & $10,345 \pm 5,569$ & 0.006 \\
\hline Total eosinophil count (cells/ml) & $105 \pm 220$ & $114 \pm 186$ & 0.8 \\
\hline Eosinopenia $(<40$ cells $/ \mathrm{ml})$ & $70(49.3 \%)$ & $18(36.7 \%)$ & 0.12 \\
\hline
\end{tabular}

Data are presented as the mean \pm standard deviation or $n(\%) .{ }^{*}$ Calculated by means of the Student $t$-test (quantitative variables) and chi-square test (qualitative variables). APACHE, Acute Physiology and Chronic Health Evaluation; ICU, intensive care unit; NA, not applicable; SAPS, Simplified Acute Physiology Score; SIRS, systemic inflammatory response syndrome; SOFA, Sequential Organ Failure Assessment.

$\mathrm{EC}=$ eosinophil count; ICU = intensive care unit; SIRS = systemic inflammatory response syndrome. 
distinguish between infection and noninfection. Although one limitation of our study was the absence of a non-SIRS group, the EC of our noninfectious SIRS group was similar to the EC found in the non-SIRS group in the study by Abidi and colleagues [1]. Another study failed to observe an association between eosinopenia and bacteremia [3].
In conclusion, eosinopenia was not a reliable marker of infection. Other analytical parameters, such as C-reactive protein, have demonstrated to be helpful not only for the diagnosis of infection but also as a marker of severity of organ dysfunction in sepsis [4].

\section{Authors' response}

Khalid Abidi, Ibtissam Khoudri, Jihane Belayachi, Naoufel Madani, Amine Ali Zeggwagh and Redouane Abouqal

Smithson and colleagues, in their letter on our report recently published in Critical Care [1], suggest that eosinopenia is not a reliable marker of infection in critically ill patients. We have demonstrated for the first time that eosinopenia is a good diagnostic marker of infection on ICU admission with good sensitivity and specificity [1].

The study performed by Smithson and colleagues has several limitations that should be considered. First, the retrospective nature of their study could cause methodological limitations, at the least because some data were not available for all patients. Second, to evaluate the usefulness of EC to distinguish between noninfectious and infectious SIRS patients, Smithson and colleagues do not describe how the infection was defined and confirmed. Third, no non-SIRS group was included, although the authors report that the EC in the noninfectious SIRS group was similar to that found in our non-SIRS group. However, ECs for non-SIRS groups from both studies should really be determined for a completely valid comparison.

\section{Competing interest}

The authors declare that they have no competing interests.

\section{References}

1. Abidi K, Khoudri I, Belayachi J, Madani N, Zekraoui A, Zeggwagh AA, Abouqal R: Eosinopenia is a reliable marker of sepsis on admission to medical intensive care units. Crit Care 2008, 12:R59.

2. Gil H, Magy N, Mauny F, Dupond JL: Value of eosinopenia in inflammatory disorders: an "old" marker revisited. Rev Med Interne 2003, 24:431-435.
3. Setterberg MJ, Newman W, Potti A, Smego RA Jr: Utility of eosinophil count as predictor of bacteremia. Clin Infect Dis 2004, 38:460-461.

4. Castelli GP, Pognani C, Meisner M, Stuani A, Bellomi D, Sqarbi L: Procalcitonin and C-reactive protein during systemic inflammatory response syndrome, sepsis and organ dysfunction. Crit Care 2004, 8:R234-R242. 